\title{
Response of mycorrhizal hybrid tomato cultivars under saline stress
}

\author{
J.-C. Huang ${ }^{1}$, W.-A. Lai ${ }^{2}$, S. Singh ${ }^{1}$, A. Hameed ${ }^{1}$ and C.-C. Young ${ }^{1,2^{*}}$
}

${ }^{1}$ Soil and Environmental Microbiology and Biochemistry Laboratory, Department of Soil and Environmental Sciences, College of Agriculture and Natural Resources, National Chung Hsing University, No. 250, Kuo Kuang Road., Taichung, 40227, Taiwan. ${ }^{2}$ Biotechnology Center, National Chung Hsing University, No. 250, Kuo Kuang Road, Taichung City 40227, Taiwan. ${ }^{*}$ Corresponding author: ccyoung@mail.nchu.edu.tw

\begin{abstract}
The response of hybrid tomato cultivars (Solanum lycopersicum L. Cvs. TSS7 and TCAV10) inoculated with arbuscular mycorrhizal fungi Claroideoglomus etunicatum (AMF-1) and Funneliformis mosseae (AMF-2) under $2 \%$ saline stress was evaluated with regard to growth, yield, quality, nutrient acquisition, AMF colonization, relative permeability and soil properties in two potted plant experiments. Inoculation with AMF-2 caused a significant increase $(\sim 30 \%)$ in the fruit yield of TCAV10, particularly under saline stress. The highest tomato juice extraction ratio was achieved for TCAV10 treated with AMF-2. Under saline stress, TCAV10 inoculated with AMF-2 demonstrated significantly enhanced $\mathrm{N}, \mathrm{P}, \mathrm{K}$ and $\mathrm{Ca}$ content in fruits; $\mathrm{N}, \mathrm{K}$ and $\mathrm{Mg}$ content in roots; and $\mathrm{N}, \mathrm{P}$ and $\mathrm{Ca}$ content in shoots. Fruits of TSS7 and TCAV10 grown under saline stress coupled with AMF-2 treatment showed a significant decrease in Na content (23.6 and 31.1\%, respectively) as compared with fruits of non-inoculated hybrid cultivars grown under saline stress. Residual $\mathrm{Na}$ in soil, AMF-2 colonization ratios and relative permeability were higher in TCAV10 inoculated with AMF-2 under saline condition compared with the non-inoculated treatments. TCAV10 inoculated with AMF-2 achieved higher fruit yield, quality and nutrient acquisition compared with the non-inoculated TCAV10. The results of this study are important for the selection of appropriate cultivars and microbial species for sustaining yield and quality under saline stress.
\end{abstract}

Keywords: Arbuscular mycorrhizal fungi, Solanum lycopersicum, inoculant, yield, nutrient content, relative permeability 


\section{Introduction}

Recent climate change is causing agricultural damage worldwide as a result of more frequent flooding and drought and increased soil salinity. Saline soils occupy more than $7 \%$ of the Earth's surface and represent a major limiting factor that decreases $>$ $20 \%$ crop production worldwide under irrigated land (Porcel et al., 2012; Feng et al., 2002). Therefore, the utilization and improvement of saline land has been a foremost challenge for researchers throughout the world. The total area of tomato cultivation in Taiwan is $\sim 4,734$ ha, and the total production is $\sim 116,034$ tons. Tomato cultivation zones are localized in central and southern Taiwan, and these zones account for $\sim 83 \%$ of the total tomato production in Taiwan, as reported by the Agriculture and Food Agency, Council of Agriculture [COA], Executive Yuan, in 2010. The saline land area is $\sim 53,000$ ha, constituting $5.8 \%$ of cultivated farmland in Taiwan (Zhu, 1999). Excessive salinity can adversely affect the physical and chemical properties of soil, microbial processes and plant growth (Yuang et al., 2007). Salt accumulates in soil predominantly as a result of strong winds, high temperatures that cause rates of evaporation to exceed precipitation near coastal areas, utilization of salt-rich industrial wastewater for irrigation, over-pumping of groundwater, excessive use of chemical fertilizers and intensive crop production (Singh et al., 2011; Siyal et al., 2002).

Tomatoes are one of the globally important crops that are known to benefit from a symbiotic relationship with mycorrhizae (Nzanza et al., 2012). An electrical conductivity (EC) of $>2.5 \mathrm{dS} \mathrm{m}^{-1}$ reduces tomato yields, as reported by Sonneveld and Welles (1988). Therefore, the exploitation of salt-tolerant soil microbes could be an alternative for plant development under conditions of extreme salinity (Giri et al., 2003). The arbuscular mycorrhizal fungi (AMF) have been studied for their ability to diminish the effects of salt on tomatoes (Daei et al., 2009; Feng et al., 2002). The AMF symbiosis has been reported to alleviate salt stress in lettuce (Lactuca sativa L.) and maize (Zea mays L.) plants besides improving the dry weights of the hosts (Aroca et al., 2013; Estrada et al., 2013).

Plants of tomato hybrid cultivar TCAV10 are indeterminate and vigorous. The weight of a single fruit is 139-184 g; fruits are firm with a crisp texture, can be transported easily and possess a good storage capacity. Fruit yield in the summer is 44.4 to 68.8 ton $\mathrm{ha}^{-1}$. The duration of time from planting to final harvest is 114-135 days, and the period of fruit production is 42-68 days. TCAV10 is resistant to bacterial wilt, Fusarium wilt and tomato mosaic virus (Lin and Hung, 2002). Plants of tomato hybrid cultivar TSS7 are also indeterminate and vigorous. The average weight of a single fruit is 106-191 g, and fruit quality, flavor and taste are good and the fruits are easy to transport and have good storage capacity. Tomato yield in the summer is $30-40$ ton $\mathrm{ha}^{-1}$. The period of fruit production is 60-75 days. TSS7 is resistant to bacterial wilt and tomato mosaic virus (Taiwan Agricultural Research Institute, 1999; Chen et al., 1994). These hybrids owe high yield potential and other numerous characteristics desirable for organic and sustainable agriculture in Taiwan. However, comparative studies on the quality and nutrient acquisition of these hybrid tomato cultivars under normal and saline stress that have been treated with AMF are scarce.

In this study, experiments were performed to evaluate the effects of the AMF Claroideoglomus etunicatum (AMF-1) and Funneliformis mosseae (AMF-2) on plant growth, fruit yield and quality, nutrient acquisition, colonization ratios, relative permeability and soil properties in two selected hybrid tomato cultivars (TSS7 and TCAV10) under saline stress.

\section{Materials and Methods}

2.1.Preparation of the inocula of arbuscular mycorrhizal fungi (AMF) 
Spores of both AMF-1 (Claroideoglomus etunicatum [syn. Glomus etunicatum] Becker \& Gerdemann) and AMF-2 (Funneliformis mosseae [syn. Glomus mosseae)] (Nicol. \& Gerd.) Gerdemann \& Trappe) were obtained from the Taiwan Agricultural Research Institute, Taichung, Taiwan. These spores were propagated using bahiagrass (Paspalum notatum Flueggé) and maize hosts. From two weeks after sowing until harvesting (90 day total growth period), 400-mL Yamazaki's nutrient solution (Wang and Wu, 1990) consisting of $\mathrm{KNO}_{3}, 0.61 \mathrm{~g} \mathrm{~L}^{-1} ; \mathrm{Ca}\left(\mathrm{NO}_{3}\right)_{2}, 0.83 \mathrm{~g}$ $\mathrm{L}^{-1} ; \mathrm{MgSO}_{4}, 0.50 \mathrm{~g} \mathrm{~L}^{-1}$; Fe-EDTA, $0.02 \mathrm{~g} \mathrm{~L}^{-1}$; H3BO3, $2.00 \mathrm{mg} \mathrm{L}^{-1} ; \mathrm{MnSO}_{4} 4 \mathrm{H}_{2} \mathrm{O}, 2.00 \mathrm{mg} \mathrm{L} \mathrm{L}^{-1} ; \mathrm{ZnSO}_{4} .7 \mathrm{H}_{2} \mathrm{O}$, $0.22 \mathrm{mg} \mathrm{L}{ }^{-1} ; \mathrm{CuSO}_{4} .5 \mathrm{H}_{2} \mathrm{O}, 0.05 \mathrm{mg} \mathrm{L} \mathrm{L}^{-1} ; \mathrm{Na}_{2} \mathrm{MoO}_{4}$, $0.02 \mathrm{mg} \mathrm{L}^{-1}$ and $\left(\mathrm{NH}_{4}\right) \mathrm{H}_{2} \mathrm{PO}_{4}, 30 \mathrm{mg} \mathrm{L}^{-1}$, was applied weekly. The plants were trimmed and irrigated until the initiation of flowering. Approximately $10 \mathrm{~g}$ of AMF-treated soil samples were collected, washed with sterile water and sieved sequentially through sieves of 60,120 and 400 mesh. The spores were collected by centrifugation after adding a $40 \%$ sucrose solution and were then counted according to method of $\mathrm{Wu}$ and $\mathrm{Lin}$ (1998).

\subsection{Cultivation of seedlings}

Two different hybrid tomato cultivars (Solanum lycopersicum L. Cvs. TSS7 and TCAV10) were chosen: Taichung-Asveg 10 (TCAV10) and Taiwan Seed Service No. 7 (TSS7). Seeds of TSS7 and TCAV10 were purchased from the Taiwan Seed Improvement and Propagation Station (TSIPS), COA, Executive Yuan, and were sown separately in plug trays with $90 \%$ BVB No. 4 peat moss (KlasmannDeilmann, Germany) and $10 \%$ sand. Two grams of soil containing spores of AMF-1 and/or AMF-2 ( 100 spores $\mathrm{g}^{-1}$ soil) were used as inoculants by mixing it with basal medium, which consists of sterile river sand and dolomite no. $3(1: 1, \mathrm{v} / \mathrm{v})$. Ten days after sowing, the seedlings were fertilized weekly with $500 \mathrm{~mL}$ of 1,000-fold diluted Plantmate No. 4 (N:P:K $=25: 5: 20)$. After four weeks, the seedlings were transplanted into a greenhouse located at the Tainan District Agricultural Research and Extension Station $\left(23^{\circ} 3^{\prime} 44.0 .01^{\prime \prime} \mathrm{N}\right.$ latitude and $120^{\circ} 20^{\prime} 25.68^{\prime \prime} \mathrm{E}$ longitude).

\subsection{Experiment 1: Impacts of AMF-1 and AMF-2 on biomass production of tomatoes under saline stress}

The seedlings for the first potted tomato experiment were transplanted on the 8th of October to study the impacts of Claroideoglomus etunicatum (AMF-1) and Funneliformis mosseae (AMF-2) inoculation on dry weights of shoot and root and moisture content (\%) of tomato plants under saline stress. For both of the potted plant experiments, a sandy loam soil was used and each pot was filled with $7 \mathrm{~kg}$ of air-dried soil. For both of the experiments, each $2 \mathrm{~g}$ soil sample $\left(\sim 100\right.$ spores $\left.\mathrm{g}^{-1}\right)$ containing either AMF-1 or/and AMF-2 was used as an inoculants along with medium individually. Ten days after transplanting, the plants of each pot were fertilized with $500 \mathrm{~mL}$ of 1,000-fold diluted Plantmate No. 4. For both the experiments, plants were watered uniformly to maintain about 25-30\% moisture level. The $\mathrm{NaCl}$ concentration (20 $\mathrm{g} \mathrm{L}^{-1}$ ) chosen in this study was suboptimal for the growth of both hybrid tomato cultivar seedlings as determined by our preliminary growth experiments (data not shown). The treatments were as follows: Control, without any amendments or inoculation; AMF-1, C.etunicatum inoculation; AMF-2, F. mosseae inoculation; AMF-1+AMF-2; Saline stress, $\mathrm{NaCl}\left(20 \mathrm{~g} \mathrm{~L}^{-1}\right)$ weekly at $10 \mathrm{~mL} \mathrm{pot}^{-1}$; Saline stress+AMF-1; Saline stress+AMF-2 and Saline stress + AMF-1+AMF-2. The mean air temperatures $\left({ }^{\circ} \mathrm{C}\right)$ during the experimental period of October and November were 26.7 and 24.3, respectively; the mean monthly relative humidity was $73 \%$ for both months; the total hours of sunshine were 177.2 and 183.8, respectively. Plants were harvested after six weeks of transplanting, fresh weight was recorded immediately, whereas dry weights was estimated after placing the sample at $70^{\circ} \mathrm{C}$ for 72 hours in a hot air oven. The shoots and roots moisture content (\%) was calculated as follows: [(fresh wt. - dry wt.) / fresh wt.] x 100. For the second experiment, AMF-2 was chosen as the inoculant because of its relatively 
better response under saline stress during the first experiment.

\subsection{Experiment 2: Inoculation of hybrid tomato cultivars with AMF-2 under saline stress}

During the following year, the second potted plant experiment was conducted on the 6th of February, in the same greenhouse. During the experimental period, for February, March, April, May and June, the mean monthly air temperature $\left({ }^{\circ} \mathrm{C}\right)$ was $19.4,21.2,25.8$, 27.8 and 28.7 , respectively; the mean monthly relative humidity (\%) was $77,75,82,81$ and 84 , respectively; and the total hours of sunshine was $159.5,173.4,146.7$, 178.1 and 168.2, respectively. About $400 \mathrm{~mL}^{\text {pot }}{ }^{-1}$ of half-strength Yamazaki's nutrient solution was used during transplanting and a full-strength solution of the same volume was used during the fruiting stage. The treatments were as follows: Control, AMF-2, Saline stress and Saline stress+AMF-2. Four fruits were retained in each inflorescence. Samples for the analysis and estimation of yield were collected four months after transplanting.

\subsection{Physicochemical and biological analysis}

\section{Soil analysis}

Initially, and after harvest, soil $\mathrm{pH}$ and $\mathrm{EC}$ were measured in extractions of $1: 1$ and $1: 5(\mathrm{w} / \mathrm{w})$, soil to water, respectively. Soil $\mathrm{N}$ content was measured by extraction, as described by Kjeldahl (1883) and Bremner (1996). Available P, K, Ca, Mg and $\mathrm{Na}$ were analyzed by inductively coupled plasma atomic emission spectroscopy (ICP-AES, 138 Ultrace, Edison, USA) using Mehlich no. 3 extraction (Mehlich, 1984). Soil organic matter (SOM) content was quantified by combustion of the soil at $430^{\circ} \mathrm{C}$ (Ben-Dor and Banin, 1989). Soil with the following properties was used: the $\mathrm{pH}$ and $\mathrm{EC}$ were 6.7 and $0.1 \mathrm{dS} \mathrm{m}^{-1}$, respectively; SOM was $27.4 \mathrm{~g} \mathrm{~kg}^{-1}$ of soil; available $\mathrm{P}, \mathrm{K}, \mathrm{Ca}, \mathrm{Na}$ and $\mathrm{Mg}$ content was 25 , $152,1,789,168$ and $241 \mathrm{mg} \mathrm{kg}^{-1}$ of soil, respectively.

\section{Fruit quality analysis}

The total soluble solids ( $\left.{ }^{\circ} \mathrm{Brix}\right)$ in the tomato fruits were measured with a Master refractometer (Atago, Tokyo, Japan). The juice extraction ratio was calculated after extracting the juice from $\sim 325 \mathrm{~g}$ of fruit pulp using a juice extractor (Panasonic, Japan).

\section{Chemical analysis of fruits, shoots and roots}

After harvesting, the different plant parts (fruits, shoots and roots) were put inside paper bags, separately, dried in an oven at $70^{\circ} \mathrm{C}$ for 72 hours, and then ground in Willey mill (Thomas model 4, Swedesboro, USA) before nutrient analysis. $\mathrm{N}$ content was determined by using the Kjeldahl (1883) method after digestion with concentrated sulfuric acid. The $\mathrm{P}, \mathrm{K}, \mathrm{Ca}, \mathrm{Mg}$ and $\mathrm{Na}$ content of the powdered fruits, shoots and roots was measured by ICP-AES after digesting the samples with a mixture $(5: 1, \mathrm{v} / \mathrm{v})$ of nitric and perchloric acids at $120-180^{\circ} \mathrm{C}$ (Miller, 1998).

\section{Root permeability analysis}

To measure the permeability of the root plasma membranes of the tomato plants, $2.5 \mathrm{~g}$ of fresh root segments was placed in a glass vial containing 25 $\mathrm{mL}$ of de-ionized water and measured for electrolytic conductivity (EC). The relative permeability of the root plasma membranes was calculated as described previously (Zwiazek and Blake, 1991):

$$
\text { Relative permeability }=\frac{\mathrm{EC} \text { of rinsates after } 30 \text { min of soaking at room temperature }}{\mathrm{EC} \text { of rinsates after heating and cooling at room temperature }} \times 100
$$




\section{Quantification of root colonization by AMF}

Six weeks after inoculation with AMF-2, five seedlings were softened with a $2.5 \% \mathrm{KOH}$ solution, root samples were chopped into $4 \mathrm{~cm}$ pieces and stained with $0.05 \%$ aniline blue for confirmation of colonization (Koske and Gemma, 1989). AMF colonization, in terms of the percentage of root segments containing AMF, was measured using a gridline intercept method (Biermann and Linderman, 1981).

\subsection{Statistical analysis}

In experiment 1 (saline stress, AMF-1 and AMF-2 separately with each hybrid cultivar) and experiment 2 (hybrid cultivars, saline stress and AMF-2), 23 factorial experiments were conducted using a randomized complete block design, with three replications. All statistical analyses were performed using the SPSS version 13.0 software package (SPSS Inc., Chicago, USA). Significance (P value) among the means of the different treatments were compared using a one-way analysis of variance (ANOVA) using Duncan's multiple range test at $p<0.05$. In experiment 2 , the effects of the treatment factors (hybrid cultivars, salinity and AMF2) and the interactions among the treatment factors (F-values) on fruit yields, colonization ratios, relative permeability, various nutrient concentrations in the fruits, shoots and roots, and soil $\mathrm{pH}$, soil EC, SOM and soil $\mathrm{Na}$ contents were analyzed with a two-way ANOVA using Turkey's test $p<0.05,0.01$ or 0.001 .

\section{Results}

\subsection{Effects of $A M F-1$ and $A M F-2$ on tomato plant biomass under saline soil conditions}

Shoots fresh, and shoots and roots dry weights were significantly higher in AMF-2 of TCAV10 when compared with control treatment. Additionally, when compared with TSS7, the TCAV10 cultivar responded better to AMF-2 specifically compared with treatments AMF-1 alone or AMF-1+AMF-2
(Figure 1). It is noteworthy that the dry biomass of shoots and roots of TCAV10 treated with AMF-2 significantly increased by 5 and $4 \%$, respectively, under saline stress, when compared with the nonsaline stress condition.

\subsection{Effects of AMF-2 on yield and quality of tomato hybrids under saline stress}

Hybrid cultivar TCAV10 grown under saline stress conditions and coupled with the AMF-2 treatment resulted in an increased fruit yield $(\sim 30 \%)$; however, no significant changes in the juice extraction ratio or in the level of soluble solids were observed when comparing the results with non-inoculated samples under saline stress (Table 1).

\subsection{Effects of AMF-2 on nutrient acquisition in tomato hybrids under saline stress}

Both TSS7 and TCAV10 grown under saline stress coupled with AMF-2 inoculation showed diminished $\mathrm{Na}$ content (Table 2) in their shoots (23.1 and 33.7\%, respectively), fruits (23.6 and $31.1 \%$, respectively) and roots (28.6 and $12.7 \%$, respectively) when compared with the non-inoculated hybrid cultivars under saline stress. Under the same experimental conditions, TSS7 and TCAV10 showed enhanced N content in their shoots (14.1 and 51.9\%, respectively), fruits (11.6 and 29.6\%, respectively) and roots (2.6 and $13.5 \%$, respectively); enhanced $P$ content in their shoots ( 24.0 and $47.6 \%$, respectively), fruits $(47.4$ and $21.2 \%$, respectively) and roots $(<1.0$ and $9.1 \%$, respectively); enhanced $\mathrm{K}$ content in their shoots (7.7 and $6.6 \%$, respectively), fruits $(<0.0$ and $21.6 \%$, respectively) and roots (5.8 and $9.3 \%$, respectively); enhanced $\mathrm{Ca}$ content in their shoots $(6.3$ and $13.2 \%$, respectively), fruits ( 40.0 and $7.1 \%$, respectively) and roots (18.5 and $4.8 \%$, respectively); and enhanced $\mathrm{Mg}$ content in their shoots (23.7 and $16.3 \%$, respectively), fruits (6.3 and $5.0 \%$, respectively) and roots (4.4 and $3.7 \%$, respectively) when compared with noninoculated samples under saline stress (Table 2 ). 
(a) TSS7

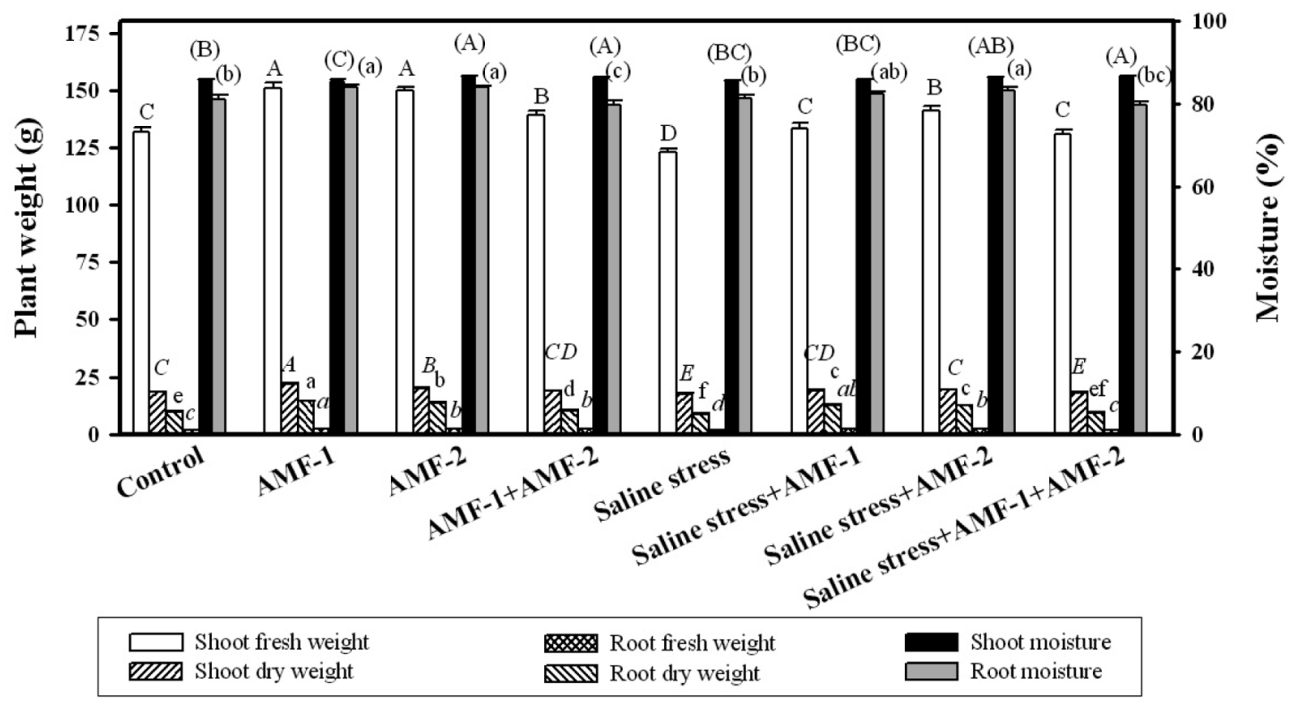

(b)TCAV10

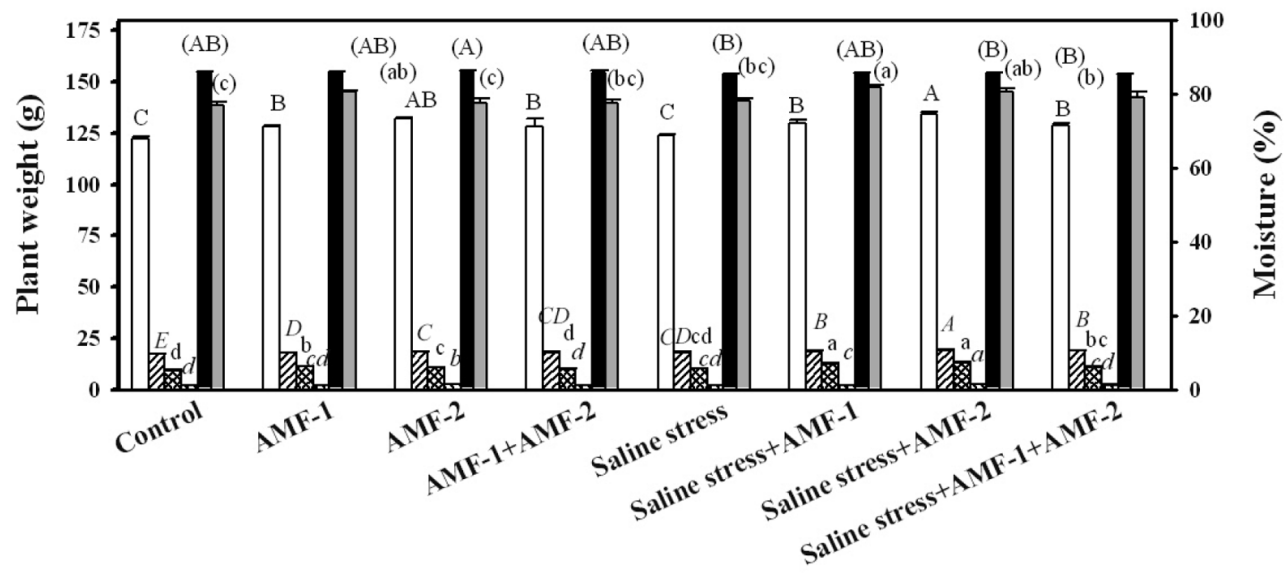

Figure 1. Effects of Claroideoglomus etunicatum (AMF-1), Funneliformis mosseae (AMF-2) and their combination on fresh and dry matter accumulation and moisture content (\%) of hybrid tomato cultivars TSS7 (a) and TCAV10 (b) grown under saline conditions. Means \pm standard deviations $(\mathrm{n}=3)$ are presented as bars. Bars with different normal and italic lowercase or capital letters are significantly different $(p<0.05)$ between treatments. Treatments: Control, without any amendments and inoculation; AMF-1, C. etunicatum; AMF-2, F. mosseae; AMF-1+AMF-2; Saline stress, $\mathrm{NaCl}\left(20 \mathrm{~g} \mathrm{~L}^{-1}\right)$ weekly at $10 \mathrm{~mL}^{-1}$ pot $^{-1}$ Saline stress $+A M F-1 ;$ Saline stress $+A M F-2$; Saline stress $+A M F-1+A M F-2$ 
Table 1. Responses of hybrid tomato cultivars inoculated with and without Funneliformis mosseae (AMF-2) on fresh fruit yield and quality under saline and non-saline conditions

\begin{tabular}{lllll} 
Cultivar & Treatment & Yield $\left(\right.$ g plant $\left.^{-1}\right)$ & Juice extraction ratio (\%) & ${ }^{\mathrm{o}}$ Brix \\
\hline TSS7 & Control & $929^{\mathrm{c}}$ & $67.4^{\mathrm{bc}}$ & \\
& AMF-2 & $1,059^{\mathrm{b}}(14)$ & $69.2^{\mathrm{ab}}(3)$ & $4.40^{\mathrm{b}}$ \\
& Saline stress & $771^{\mathrm{e}}$ & $64.1^{\mathrm{c}}$ & $4.78^{\mathrm{a}}(11)$ \\
& Saline stress+AMF-2 & $811^{\mathrm{de}}(5)$ & $67.8^{\mathrm{b}}(6)$ & $5.00^{\mathrm{a}}(6)$ \\
TCAV10 & Control & $849^{\mathrm{d}}$ & $65.3^{\mathrm{bc}}$ & $4.70^{\mathrm{ab}}$ \\
& AMF-2 & $912^{\mathrm{cd}}(7)$ & $75.2^{\mathrm{a}}(15)$ & $4.90^{\mathrm{a}}(4)$ \\
& Saline stress & $926^{\mathrm{c}}$ & $67.7^{\mathrm{bc}}$ & $4.89^{\mathrm{a}}$ \\
& Saline stress+AMF-2 & $1,201^{\mathrm{a}}(30)$ & $69.7^{\mathrm{ab}}(3)$ & $5.08^{\mathrm{a}}(4)$ \\
\hline
\end{tabular}

(Control, without any amendments and inoculation; Saline stress, $\mathrm{NaCl}\left(20 \mathrm{~g} \mathrm{~L}^{-1}\right)$ weekly at $10 \mathrm{~mL}^{\text {pot }}{ }^{-1}$; AMF-2; inoculation with F. mosseae; Saline stress $+A M F-2$. Means within each column followed by the same letter are not significantly different at $p<0.05$ using Duncan's multiple range test. Data in parentheses represent relative \% increases as compared to respective non-inoculated controls.)

\subsection{Impact of $A M F-2$ and saline treatment on root} colonization, relative permeability and soil properties

The hybrid cultivar TCAV10 recorded relatively higher colonization ratios when grown under saline stress than when grown under non-saline stress conditions; however, TSS7 inoculated with $A M F-2$ under non-saline stress had a significantly higher root colonization ratio (Figure 2).

There was a significant increase in electrolyte permeability in the root plasma membranes when the tomato plants were treated with saline and AMF-2 compared with the other treatments (Figure 3).

At harvest, the soil EC was significantly higher in the treatments under saline stress. The Na content of the soil was significantly higher in both TSS7 and TCAV10 plants treated with saline and inoculated with AMF-2 (Table 3).

\subsection{Effects of $A M F-2$, hybrid cultivars and salinity on} fruit yield, relative permeability, colonization ratios, nutrient acquisition, soil $\mathrm{pH}$, soil EC, SOM and soil $\mathrm{Na}$

In this study, saline stress significantly influenced the $\mathrm{Na}$ content of shoots, roots and fruits, irrespective of the fact that the treatment did not significantly change the fruit yield. Inoculation with AMF significantly influenced the fruit yield. AMF inoculation also significantly influenced the mineral and nutrient content of the fruits, shoots and roots. In this study, the hybrid cultivars significantly influenced the fruit yield. 
AMF inoculation also significantly influenced the mineral and nutrient content of the fruits, shoots and roots. In this study, the hybrid cultivars significantly influenced the fruit yield. Hybrid cultivars also showed significant changes in the mineral and nutrient composition of their fruits and displayed significant alterations in some of the nutrients in their roots and shoots. The interaction between salinity and AMF-2 influence the $\mathrm{Na}, \mathrm{P}$ and $\mathrm{N}$ content of the fruit, the $\mathrm{Na}$ content of the shoots and the $\mathrm{Na}$ and $\mathrm{P}$ content of the roots. The interaction between the salinity and the hybrid cultivar significantly influenced the fruit yield. Additionally, the $\mathrm{Na}$ and $\mathrm{Mg}$ content of the fruit, the $\mathrm{N}$, $\mathrm{Mg}$ and $\mathrm{Na}$ content of the shoots, the $\mathrm{N}, \mathrm{K}, \mathrm{Ca}, \mathrm{Mg}$ and $\mathrm{Na}$ content of the roots were influenced significantly by the interaction between salinity and the hybrid cultivars.
The interaction between AMF-2 and the hybrid cultivars significantly influenced the fruit yield. The $\mathrm{Na}, \mathrm{K}, \mathrm{N}$, and $\mathrm{Ca}$ content of fruits, the $\mathrm{P}, \mathrm{N}$ and $\mathrm{Ca}$ content of roots and the $\mathrm{Na}, \mathrm{P}$ and $\mathrm{N}$ content of shoots were significantly influenced by the interaction between AMF-2 and the hybrid cultivars. The interaction among salinity, AMF-2 and the hybrid cultivars significantly influenced the fruit yield. Nevertheless, the interactions among salinity, AMF2 and the hybrid cultivar significantly influenced the $\mathrm{N}$ and $\mathrm{Na}$ content of fruits and the $\mathrm{P}$ and $\mathrm{Na}$ content of roots. Salinity was positively correlated with soil $\mathrm{pH}, \mathrm{EC}$ and Na. The interaction among, saline stress and AMF-2, saline stress and hybrid cultivar, and saline stress, AMF-2 and hybrid cultivar significantly influenced the soil $\mathrm{Na}$ (Table 4).

Table 2. Nutrient content in the dried shoots, fruits and roots of hybrid tomato cultivars inoculated with and without Funneliformis mosseae (AMF-2) under saline and non-saline conditions

\begin{tabular}{|c|c|c|c|c|c|c|c|c|c|c|c|c|c|c|c|c|c|c|c|}
\hline \multirow{2}{*}{ Cultivar } & \multirow{2}{*}{ Treatment } & \multicolumn{6}{|c|}{ Shool (g kg') } & \multicolumn{6}{|c|}{ Fruाt(gkg") } & \multicolumn{6}{|c|}{ Root (gkg $)$} \\
\hline & & $\mathrm{N}$ & $\mathrm{P}$ & $\mathrm{K}$ & $\mathrm{Ca}$ & $\mathrm{Mg}$ & $\mathrm{Na}$ & $\mathrm{N}$ & P & $\mathrm{K}$ & $\mathrm{Ca}$ & $\mathrm{Mg}$ & $\mathrm{Na}$ & $\mathrm{N}$ & $\mathrm{P}$ & $\mathrm{K}$ & $\mathrm{Ca}$ & $\mathrm{Mg}$ & $\mathrm{Na}$ \\
\hline \multirow[t]{4}{*}{ TSS7 } & Control & $19.3^{\mathrm{ca}}$ & $2.7^{\circ}$ & $28.5^{\mathrm{oc}}$ & $17.7^{0 \mathrm{cc}}$ & $4.4^{\mathrm{avo}}$ & $1.9^{c}$ & $15.2^{2}$ & $2.7^{\mathrm{a}}$ & $37.4^{100}$ & $1.1^{2}$ & $3.3^{\mathrm{avo}}$ & $0.3^{4}$ & $12.8^{\circ}$ & $1.2^{c}$ & $18.1^{\circ}$ & $6.3^{\mathrm{oc}}$ & $4.7^{\mathrm{at}}$ & $1.6^{3}$ \\
\hline & AMF-2 & $22.8^{c}$ & $3.0^{\mathrm{a}}$ & $31.3^{\mathrm{ab}}$ & $19.6^{\mathrm{ab}}$ & $4.9 \mathrm{a}^{\mathrm{b}}$ & $2.1^{c}$ & $16.1^{\mathrm{e}}$ & $3.0^{\text {cd }}$ & $41.1^{\mathrm{ab}}$ & $1.5^{\mathrm{a}}$ & $3.5^{\mathrm{a}}$ & $0.4^{c}$ & $13.1^{\mathrm{ab}}$ & $1.4^{\mathrm{a}}$ & $19.6^{\mathrm{a}}$ & $7.7^{\mathrm{a}}$ & $4.9^{c}$ & $2.2^{e}$ \\
\hline & Saline stress & $18.5^{\mathrm{d}}$ & $2.5^{\mathrm{b}}$ & $26.1^{c}$ & $17.6^{\mathrm{bc}}$ & $3.8^{\mathrm{b}}$ & $3.7^{\mathrm{a}}$ & $13.8^{f}$ & $1.9^{e}$ & $37.7^{\mathrm{ab}}$ & $1.0^{c}$ & $3.2^{\mathrm{b}}$ & $0.7^{\mathrm{a}}$ & $11.6^{\mathrm{d}}$ & $1.3^{\mathrm{b}}$ & $17.0^{c}$ & $5.4^{\mathrm{d}}$ & $4.5^{e}$ & $7.4^{\mathrm{b}}$ \\
\hline & Saline stress+AMF-2 & $21.1^{\mathrm{c}}$ & $3.1^{\mathrm{a}}$ & $28.1^{\mathrm{bc}}$ & $18.7^{\mathrm{b}}$ & $4.7^{\mathrm{ab}}$ & $2.8^{\mathrm{b}}$ & $15.4^{e}$ & $2.8^{\mathrm{d}}$ & $37.4^{\mathrm{ab}}$ & $1.4^{\mathrm{b}}$ & $3.4^{\mathrm{ab}}$ & $0.6^{\mathrm{b}}$ & $11.9^{\text {cd }}$ & $1.3^{\mathrm{b}}$ & $18.3^{\mathrm{b}}$ & $6.4^{\mathrm{b}}$ & $4.7^{\mathrm{de}}$ & $5.3^{\mathrm{d}}$ \\
\hline \multirow{4}{*}{ TCAV10 } & Control & $24.2^{\mathrm{bc}}$ & $1.9^{c}$ & $29.6^{\mathrm{ab}}$ & $17.4^{c}$ & $3.9^{\mathrm{b}}$ & $1.6^{\mathrm{d}}$ & $21.3^{c}$ & $3.9^{\mathrm{b}}$ & $28.3^{c}$ & $1.5^{\mathrm{a}}$ & $2.2^{\mathrm{d}}$ & $0.3^{\mathrm{de}}$ & $12.1^{\mathrm{c}}$ & $1.2^{\mathrm{cd}}$ & $15.3^{e}$ & $6.0^{c}$ & $4.6^{\mathrm{e}}$ & $1.8^{f}$ \\
\hline & AMF-2 & $36.3^{\mathrm{a}}$ & $3.0^{\mathrm{a}}$ & $31.8^{\mathrm{a}}$ & $19.8^{\mathrm{a}}$ & $4.5^{\mathrm{ab}}$ & $1.4^{\mathrm{e}}$ & $22.9^{\mathrm{b}}$ & $4.3^{\mathrm{a}}$ & $43.9^{\mathrm{a}}$ & $1.5^{\mathrm{a}}$ & $2.6^{c}$ & $0.3^{e}$ & $13.4^{\mathrm{a}}$ & $1.2^{\mathrm{cd}}$ & $17.3^{\mathrm{c}}$ & $6.5^{\mathrm{b}}$ & $4.7^{\mathrm{d}}$ & $1.4^{\mathrm{h}}$ \\
\hline & Saline stress & $25.2^{\mathrm{b}}$ & $2.1 \mathrm{c}$ & $27.3^{\mathrm{bc}}$ & $17.4^{c}$ & $4.3^{\mathrm{ab}}$ & $2.9^{\mathrm{b}}$ & $18.9^{\mathrm{d}}$ & $3.3 \mathrm{c}$ & $35.7^{\mathrm{b}}$ & $1.4^{\mathrm{b}}$ & $2.0^{e}$ & $0.6^{\mathrm{b}}$ & $11.9^{\text {cd }}$ & $1.1^{\mathrm{d}}$ & $15.1^{e}$ & $6.2^{\mathrm{bc}}$ & $5.4^{\mathrm{b}}$ & $7.8^{\mathrm{a}}$ \\
\hline & Saline stress+AMF-2 & $38.1^{\mathrm{a}}$ & $3.1^{\mathrm{a}}$ & $29.1^{\mathrm{b}}$ & $19.7^{\mathrm{ab}}$ & $5.0^{\mathrm{a}}$ & $1.9^{c}$ & $24.5^{\mathrm{a}}$ & $4.0^{\mathrm{b}}$ & $43.4^{\mathrm{a}}$ & $1.5^{\mathrm{a}}$ & $2.1^{\text {de }}$ & $0.4^{\text {cd }}$ & $13.5^{\mathrm{a}}$ & $1.2^{\mathrm{cd}}$ & $16.5^{d}$ & $6.5^{\mathrm{b}}$ & $5.6^{\mathrm{a}}$ & $6.9^{\mathrm{cW}}$ \\
\hline
\end{tabular}

(Control, without any amendments and inoculation; Saline stress, $\mathrm{NaCl}\left(20 \mathrm{~g} \mathrm{~L}^{-1}\right)$ weekly at $10 \mathrm{~mL}$ pot ${ }^{-1}$; AMF-2, inoculation with F. mosseae; Saline stress $+A M F-2$ Means within each column followed by the same letter are not significantly different at $p<0.05$ using Duncan's multiple range test.) 


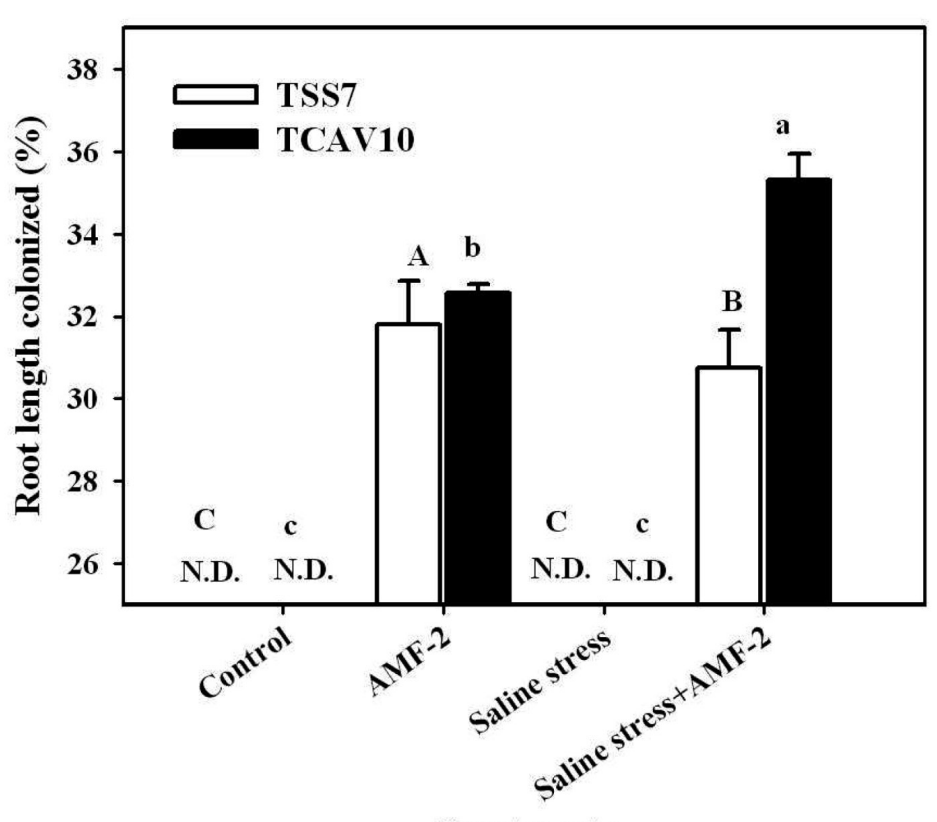

Treatments

Figure 2. Colonization ratios of hybrid tomato cultivar (TSS7 and TCAV10) roots inoculated with and without Funneliformis mosseae (AMF-2) under saline and non-saline conditions. Data labeled with different letters are significantly different $(p<0.05)$ between treatments. Control, without any amendments and inoculation; Saline stress, $\mathrm{NaCl}\left(20 \mathrm{~g} \mathrm{~L}^{-1}\right)$ weekly at $10 \mathrm{~mL}^{-1}$ pot $^{-1} A M F-2, F$. mosseae inoculation; Saline stress $+A M F-2$. N.D, not detectable.

\section{Discussion}

Inoculation with AMF-2 under saline conditions resulted in a significant increase in the biomass of both shoots and roots in Cvs. TSS7 and TCAV10. Successful colonization with AMF-2 should be one of the primary strategies for improving TCAV10 under saline stress conditions, as evidenced in this study. This result is different from the data reported by Ghazi et al. (2001) because of the different salinity levels and hybrid cultivars of tomato that were tested in their experiments. Under saline conditions the impacts of AMF-2 inoculation on growth, fruit yield and quality of the tomatoes were similar to the results reported in tomato plants that had been inoculated with Glomus mosseae, showing increased shoot dry weight under both normal and saline conditions (Nzanza et al., 2012). Additionally, the combination of AMF-1 and AMF-2 showed an antagonistic response for shoot and root dry matter production in the hybrid tomato cultivars analyzed in this study. Thus, it is reasonable to avoid inoculating the present hybrid cultivars of tomato using the combination of AMF-1 and AMF-2. Under non-saline soil conditions, TSS7 treated with AMF-1 responded better, whereas the response of AMF-2-treated TCAV10 was superior under saline soil 
conditions. Therefore, it is recommended that hybrid tomato cultivars and AMF inoculants should be selected according to the soil conditions and the corresponding responses of AMF types. Nzanza et al. (2012) reported that, under normal conditions, tomato nurseries inoculated with Glomus mosseae experienced stimulated levels of yield, total soluble solids and shoot dry weights. Debouba et al. (2006) reported that tomato plants inoculated with AMF showed greater shoot and root dry matter accumulation when irrigated with either saline or non-saline water. Enhanced fruit yield with unaltered quality might be the typical response of TCAV10 under saline stress if it were inoculated with AMF-2.

The plant species, cultivar and growing conditions have been reported to influence AMF symbiosis and the associated nutrient acquisition (Daei et al., 2009; Giri et al., 2003), as evidenced in the present study. Evelin et al. (2009) reviewed the mechanisms that are employed by AMF for enhancing the salt tolerance of the host plant, including enhanced nutrient acquisition $\left(\mathrm{P}, \mathrm{N}, \mathrm{Mg}\right.$ and $\mathrm{Ca}$ ), maintenance of the $\mathrm{K}^{+}: \mathrm{Na}^{+}$ratio, biochemical features (photosynthetic efficiency, relative permeability, water status, abscisic acid accumulation nodulation and nitrogen fixation) and molecular changes (the expression of the genes PIP, $\mathrm{Na}^{+} / \mathrm{H}^{+}$anti-porters, Lsncedm Lslea and LsP5CS and ultra-structural changes).

Salinity is a factor that significantly influences the N, $\mathrm{P}, \mathrm{Ca}$ and $\mathrm{Mg}$ content of fruits as well as shoots and roots, as determined in this study. The detrimental effects of salt on plant growth result from ion $\left(\mathrm{Na}^{+}, \mathrm{Cl}^{-}\right.$, and $\mathrm{Br}$ - ions) toxicity, which also causes soil and plant osmotic imbalances (Al-Karaki, 2000). Our results showed that the salt concentrations used in the present study significantly altered the key nutrient content of hybrid tomato cultivars, which is probably due to the osmotic imbalance.

The inoculation of tomato hybrid cultivars with AMF demonstrated higher fresh and dry matter and moisture content (\%) in both shoots and roots, and higher fruit yields. Interestingly, shoot dry weights, a characteristic that is often measured as an indicator of growth and yield, always showed lower heritability than did the measures of ion content and water processing, when estimated in 135 recombinant inbred lines from a cross between Solanum lycopersicum $\times S$. pimpinellifolium in six plants per genotype, grown in hydroponics, after 5 weeks of salt treatments ( 9 week old plants). These results indicate the importance of using both ion content and water processing traits rather than using dry weight alone (Cuartero et al., 2002). The hybrid cultivars used in this study showed higher heritability levels.

As indicated by previous investigations, the tomato plant is moderately sensitive to salinity; nevertheless, considerable differences between the responses of different hybrid cultivars can be observed with respect to saline stress. The exact level might vary depending on hybrid cultivar sensitivity and environmental conditions. Moreover, most experiments concerned with the responses of tomatoes to moderate salt stress revealed a higher sensitivity to salinity in the yield of fresh fruit compared with the sensitivity of the vegetative growth (Passam et al., 2007). It has been reported that AMF inoculation was more effective at enhancing shoot dry matter and $\mathrm{P}$ acquisition in the salt-sensitive cultivar Marriha than in the salt-tolerant cultivar Pello under salt levels of $7.1 \mathrm{dS} \mathrm{m}^{-1}$ (Ghazi et al., 2001). The host plant species, cultivar and growth conditions can influence the effects of AMF symbiosis on nutrient acquisition (Ghazi et al., 2001), as evidenced in the present study. Our study reveals the significance of selecting the AMF strains according to the soil conditions, crop species and cultivars for sustainable and quality food production in the era of climate change.

AMF-2 inoculation enables plants to sustain a higher electrolyte concentration compared with nonmycorrhizal plants by maintaining improved integrity and stability of their cell membranes (Feng et al., 2002). However, salinity and mycorrhizal inoculation caused higher permeability of the root plasma membranes of the tomato plants in the present study. 
AMF alters plant metabolism and modifies plant physiology by increasing the rate of photosynthesis, altering the position of photosynthates in the shoots and roots and affecting the uptake of nutrients from the soil, resulting in altered nutrient concentrations in plants. These changes in the tissues result in the structural and biochemical alteration of root cells and membrane permeability, hence affecting the quality and quantity of root exudates (Linderman and Davis 2004). Soil pH was relatively unaffected among the treatments, which shows that the buffering capacity of the soil restrict an alteration in the soil $\mathrm{pH}$. The soil EC was significantly higher under the saline treatment inoculated with AMF-2, which reveals that AMF-2 colonization reduces $\mathrm{Na}$ uptake by tomato plants, so that the soil $\mathrm{Na}$ content remained higher at harvest.

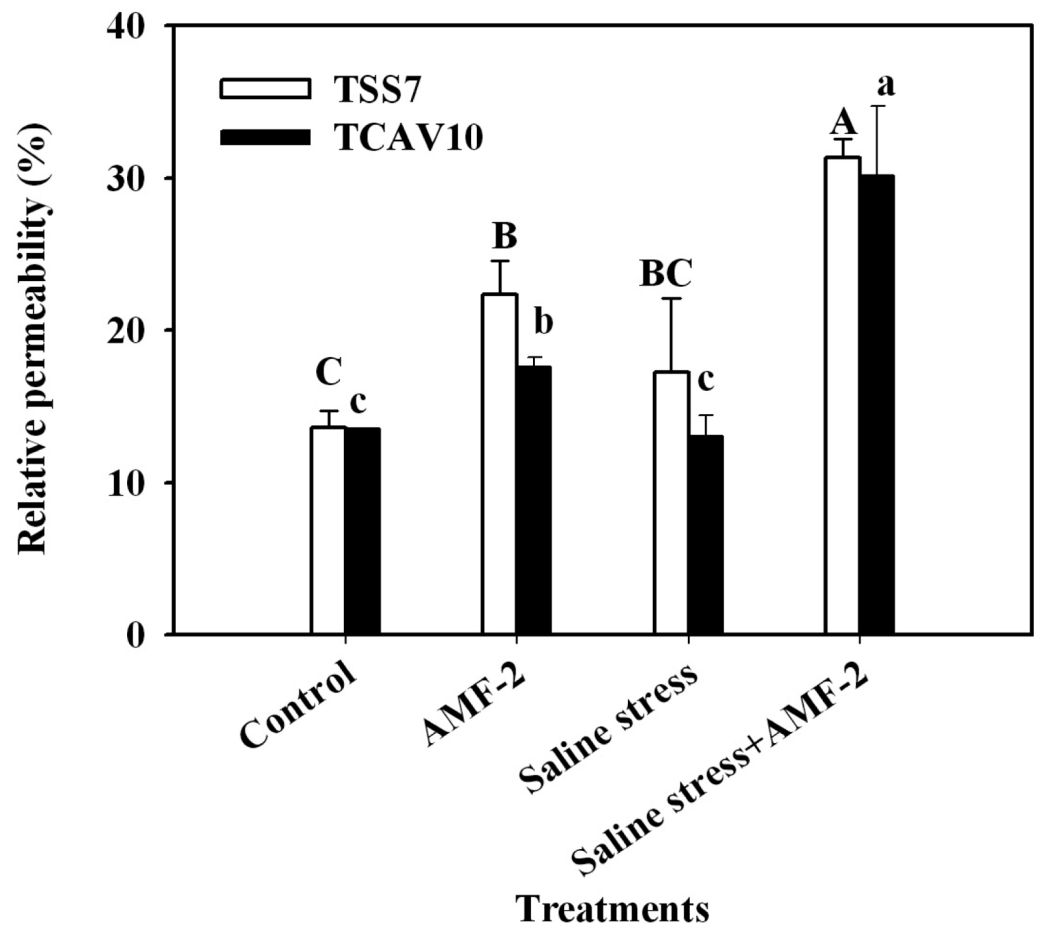

Figure 3. Relative permeability of hybrid tomato cultivar (TSS7 and TCAV10) root plasma membranes inoculated with and without Funneliformis mosseae (AMF-2) under saline and non-saline conditions. Data labeled with different letters are significantly different $(p<0.05)$ between treatments. Control, without any amendments and inoculation; Saline stress, $\mathrm{NaCl}\left(20 \mathrm{~g} \mathrm{~L}^{-1}\right)$ weekly at $10 \mathrm{~mL}^{-1}$ pot $^{-1}$ AMF-2, F. mosseae inoculation; Saline stress $+A M F-2$. 
Table 3. The effects of hybrid tomato cultivars inoculated with and without Funneliformis mosseae (AMF-2) on dried soil properties at harvest under saline and non-saline conditions

\begin{tabular}{llcccc}
\hline Cultivar & Treatment & $\begin{array}{c}\mathrm{pH} \\
(1: 1, \mathrm{w} / \mathrm{w})\end{array}$ & $\begin{array}{c}\mathrm{EC} \\
\left.(\mathrm{dS} \mathrm{m})^{-1} ; 1: 5, \mathrm{w} / \mathrm{w}\right)\end{array}$ & $\begin{array}{c}\mathrm{SOM} \\
(\%, \mathrm{w} / \mathrm{w})\end{array}$ & $\begin{array}{c}\mathrm{Na} \\
\left(\mathrm{mg} \mathrm{kg}^{-1}\right)\end{array}$ \\
\hline TSS7 & Control & $7.3^{\mathrm{a}}$ & $0.18^{\mathrm{b}}$ & $3.1^{\mathrm{a}}$ & $287^{\mathrm{f}}$ \\
& AMF-2 & $7.2^{\mathrm{ab}}$ & $0.17^{\mathrm{b}}$ & $3.0^{\mathrm{a}}$ & $338^{\mathrm{e}}$ \\
& Saline stress & $7.2^{\mathrm{ab}}$ & $0.62^{\mathrm{a}}$ & $3.0^{\mathrm{a}}$ & $758^{\mathrm{b}}$ \\
& Saline stress+AMF-2 & $7.1^{\mathrm{ab}}$ & $0.62^{\mathrm{a}}$ & $3.0^{\mathrm{a}}$ & $801^{\mathrm{a}}$ \\
TCAV10 & Control & $7.2^{\mathrm{ab}}$ & $0.17^{\mathrm{b}}$ & $3.0^{\mathrm{a}}$ & $373^{\mathrm{d}}$ \\
& AMF-2 & $7.2^{\mathrm{ab}}$ & $0.18^{\mathrm{b}}$ & $2.9^{\mathrm{a}}$ & $292^{\mathrm{f}}$ \\
& Saline stress & $7.2^{\mathrm{ab}}$ & $0.60^{\mathrm{a}}$ & $3.0^{\mathrm{a}}$ & $657^{\mathrm{c}}$ \\
& Saline stress+AMF-2 & $7.1^{\mathrm{b}}$ & $0.60^{\mathrm{a}}$ & $3.0^{\mathrm{a}}$ & $794^{\mathrm{a}}$ \\
\hline
\end{tabular}

(Control, without any amendments and inoculation; Saline stress, $\mathrm{NaCl}\left(20 \mathrm{~g} \mathrm{~L}^{-1}\right)$ weekly at $10 \mathrm{~mL} \mathrm{pot}^{-1}$; AMF-2, inoculation with $F$. mosseae; Saline stress $+A M F-2$. Means within each column followed by the same letter are not significantly different at $p<0.05$ using Duncan's multiple range test. 
Table 4. Significance levels (F-values) of treatments and treatment interactions on measured variables as determined

\begin{tabular}{|c|c|c|c|c|c|c|c|}
\hline Trait & Salinity & $\begin{array}{l}\text { AMF-2 } \\
\text { status }\end{array}$ & $\begin{array}{l}\text { Cultivar } \\
\text { (C) }\end{array}$ & $\begin{array}{l}\text { Salt } \times \\
\text { AMF-2 }\end{array}$ & Salt $\times C$ & $\begin{array}{l}\text { AMF-2 } \times \\
\text { C }\end{array}$ & $\begin{array}{l}\text { Salt } \times \\
\text { AMF-2 } \times \text { C }\end{array}$ \\
\hline Fruit yield & $0.4^{\mathrm{ns}}$ & $63.6^{* *}$ & $24.9^{* * *}$ & $3.6^{\mathrm{ns}}$ & $146.2^{* * *}$ & $6.9^{*}$ & $22.5^{* * *}$ \\
\hline$\%$ RLC & $3.7^{\mathrm{ns}}$ & $20928^{* * *}$ & $35.0^{* * *}$ & $3.7^{\mathrm{ns}}$ & $17.8^{* *}$ & $35.0^{* * *}$ & $17.8^{* *}$ \\
\hline$\%$ RP & $28.1^{* * * *}$ & $102.4^{* * *}$ & $2.8^{\text {ns }}$ & $13.9^{* *}$ & $0.5^{\mathrm{ns}}$ & $0.2^{\mathrm{ns}}$ & $7.4^{*}$ \\
\hline Fruit N & $6.4^{*}$ & $76.2^{* * *}$ & $580.1^{\text {*** }}$ & $19.0^{* * *}$ & $1.5^{\mathrm{ns}}$ & $17.9^{* *}$ & $8.4^{*}$ \\
\hline Fruit P & $45.6^{* * *}$ & $56.0^{* * *}$ & $283.8^{* * *}$ & $7.8^{*}$ & $0.0^{\mathrm{ns}}$ & $0.7^{\text {ns }}$ & $0.4^{\mathrm{ns}}$ \\
\hline Fruit K & $0.3^{\mathrm{ns}}$ & $19.3^{* * *}$ & $0.1^{\mathrm{ns}}$ & $3.9^{\text {ns }}$ & $3.0^{\mathrm{ns}}$ & $10.9^{* *}$ & $0.4^{\mathrm{ns}}$ \\
\hline Fruit $\mathrm{Ca}$ & $13.1^{* *}$ & $138.5^{* * *}$ & $163.2^{* * *}$ & $0.8^{\mathrm{ns}}$ & $1.3^{\mathrm{ns}}$ & $40.5^{* * *}$ & $3.9^{\mathrm{ns}}$ \\
\hline Fruit $\mathrm{Mg}$ & $24.0^{* * *}$ & $18.8^{* *}$ & $454.2^{* * *}$ & $2.2^{\mathrm{ns}}$ & $9.2^{* *}$ & $0.3^{\mathrm{ns}}$ & $3.1^{\mathrm{ns}}$ \\
\hline Fruit $\mathrm{Na}$ & $341.5^{* * *}$ & $44.4^{* * *}$ & $120.7^{* * *}$ & $61.0^{* * *}$ & $23.0^{* * *}$ & $5.0^{*}$ & $5.4^{*}$ \\
\hline Shoot N & $0.0^{\mathrm{ns}}$ & $297.0^{* * *}$ & $539.8^{* * *}$ & $0.0^{\mathrm{ns}}$ & $8.7^{* *}$ & $108.6^{* * *}$ & $0.9^{\mathrm{ns}}$ \\
\hline Shoot P & $1.2^{\mathrm{ns}}$ & $160.1^{* * *}$ & $19.1^{* * *}$ & $0.3^{\mathrm{ns}}$ & $1.6^{\mathrm{ns}}$ & $27.8^{* * *}$ & $3.1^{\mathrm{ns}}$ \\
\hline Shoot K & $20.7^{* * *}$ & $14.0^{* *}$ & $2.7^{\mathrm{ns}}$ & $0.3^{\mathrm{ns}}$ & $0.1^{\mathrm{ns}}$ & $0.1^{\mathrm{ns}}$ & $0.0^{\mathrm{ns}}$ \\
\hline Shoot Ca & $1.4^{\mathrm{ns}}$ & $60.3^{* * *}$ & $0.7^{\mathrm{ns}}$ & $1.0^{\mathrm{ns}}$ & $0.6^{\mathrm{ns}}$ & $2.7^{\mathrm{ns}}$ & $0.5^{\mathrm{ns}}$ \\
\hline Shoot Mg & $0.1^{\text {ns }}$ & $30.4^{* * *}$ & $0.1^{\mathrm{ns}}$ & $0.9^{\mathrm{ns}}$ & $9.9^{* *}$ & $0.0^{\mathrm{ns}}$ & $0.5^{\mathrm{ns}}$ \\
\hline Shoot Na & $438.4^{* * *}$ & $81.8^{* * *}$ & $161.7^{* * *}$ & $72.7^{* * *}$ & $13.4^{* *}$ & $7.2^{*}$ & $2.2^{\mathrm{ns}}$ \\
\hline Root N & $38.3^{* * * *}$ & $77.9^{* * *}$ & $13.8^{* *}$ & $0.5^{\mathrm{ns}}$ & $32.3^{\text {*** }}$ & $32.3^{* * *}$ & $0.6^{\mathrm{ns}}$ \\
\hline Root P & $1.0 \mathrm{~ns}$ & $28.9^{* * * *}$ & $81.9^{* * *}$ & $5.1^{*}$ & $0.3^{\text {ns }}$ & $5.8^{*}$ & $12.5^{* *}$ \\
\hline Root K & $73.9^{* * *}$ & $243.0^{* * * *}$ & $481.0^{* * * *}$ & $3.7^{\mathrm{ns}}$ & $11.4^{* *}$ & $2.8^{\mathrm{ns}}$ & $0.8^{\mathrm{ns}}$ \\
\hline Root Ca & $41.5^{* * *}$ & $126.0^{* * *}$ & $4.6^{*}$ & $1.8^{\mathrm{ns}}$ & $67.8^{* * *}$ & $30.1^{* * *}$ & $0.5^{\mathrm{ns}}$ \\
\hline Root Mg & $141.3^{* * *}$ & $41.7^{* * *}$ & $175.9^{* * *}$ & $1.3^{\text {ns }}$ & $361.1^{* * *}$ & $0.2^{\mathrm{ns}}$ & $3.4^{\mathrm{ns}}$ \\
\hline Root Na & $22739.4^{\text {*** }}$ & $517.6^{* * *}$ & $97.5^{* * *}$ & $552.1^{* * *}$ & $377.1^{* * * *}$ & $0.3^{\text {ns }}$ & $261.6^{* * *}$ \\
\hline Soil pH & $6.8^{*}$ & $0.7^{\mathrm{ns}}$ & $1.8^{\mathrm{ns}}$ & $0.0^{\mathrm{ns}}$ & $1.3^{\mathrm{ns}}$ & $0.0^{\mathrm{ns}}$ & $0.0^{\mathrm{ns}}$ \\
\hline Soil EC & $3120^{\text {*** }}$ & $0.0^{\mathrm{ns}}$ & $0.7^{\mathrm{ns}}$ & $0.0^{\mathrm{ns}}$ & $1.1^{\mathrm{ns}}$ & $0.7^{\mathrm{ns}}$ & $0.4^{\mathrm{ns}}$ \\
\hline SOM & $0.2^{\text {ns }}$ & $0.2^{\mathrm{ns}}$ & $0.1^{\mathrm{ns}}$ & $0.5^{\mathrm{ns}}$ & $0.0^{\mathrm{ns}}$ & $1.1^{\mathrm{ns}}$ & $0.0^{\mathrm{ns}}$ \\
\hline Soil $\mathrm{Na}$ & $4246^{* * *}$ & $32.6^{* * *}$ & $6.8^{*}$ & $62.9^{* * *}$ & $31.1^{* * *}$ & $2.0^{\mathrm{ns}}$ & $74.6^{* * *}$ \\
\hline
\end{tabular}

$(*, * *, * * *$ and ns indicate significant differences at $p<0.05, p<0.01, p<0.001$ and non-significant differences, respectively, as determined using Duncan's multiple range tests. \% RLC, percentage of relative root length colonized, \% RP, percentage of relative permeability.) 


\section{Conclusions}

Under conditions of experimental saline stress, an inoculation with $F$. mosseae (AMF-2) significantly increased the fruit yield, as well as the shoot and root biomass of selected hybrid tomato cultivars (TSS7 and TCAV10). The response of TCAV10 was better than that of TSS7 under saline stress. Additionally, under saline stress, both of the hybrid cultivars inoculated with $F$. mosseae showed a decreased content of $\mathrm{Na}$ and enhanced $\mathrm{N}, \mathrm{P}, \mathrm{K}$ and $\mathrm{Ca}$ content in the fruits of TCAV10 when compared with those of the noninoculated plants under saline treatment. At harvest, the soil $\mathrm{Na}$ content was higher in the saline treatments inoculated with AMF-2, which reveals that AMF-2 colonization successfully reduces the $\mathrm{Na}$ uptake by tomato plants and helps stimulate nutrient acquisition, as evidenced by the higher root permeability. Therefore, inoculation with $F$. mosseae enhanced the nutrient acquisition in the shoots, fruits and roots of the Cvs. TSS7 and TCAV10 under saline stress. Overall, TCAV10 responded better compared with TSS7 to inoculation with $F$. mosseae under saline stress.

\section{Acknowledgements}

The research was kindly supported by a grant from the National Science Council, COA, Executive Yuan and partly by the Ministry of Education, Taiwan, under the ATU plan. The authors are thankful to Dr. Su-Chen Lin from Taiwan Agricultural Institute for providing mycorrhizae; to the Agricultural Research Institute, COA for providing the experimental facilities and site management of the Chi-Ko farm, Taiwan.

\section{References}

Al-Karaki, G. N. 2000. Growth and mineral acquisition by mycorrhizal tomato grown under salt stress. Mycorrhiza. 10, 51-54.
Aroca, R., Ruiz-Lozano, J.M., Zamarreño, Á.M., Paz, J.A., García-Mina, J.M., Pozo, M.J., López-Ráez, J.A. 2013. Arbuscular mycorrhizal symbiosis influences strigolactone production under salinity and alleviates salt stress in lettuce plants. J. Plant Physiol. 170, 47-55.

Ben-Dor, E., Banin, A. 1989. Determination of organic matter content in arid-zone soils using a simple loss-on-ignition method. Commun Soil Sci. Plant Anal. 20, 1675-1695.

Biermann, B.J., Linderman, R.G. 1981. Quantifying vesicular-arbuscular mycorrhizae: a proposed method towards standardization. New Phytol. 87, 63-67.

Bremner, J.M. 1996. Nitrogen Total. In: D. L. Sparks (ed). Methods of Soil Analysis, part 3: Chemical Methods. Soil Science Society of America Inc., Madison, pp: 1085-1121.

Chen, S.Y., Li, M.J., Shiau, F.L., Yang, T.C. 1994. An novel cultivar. TSS7 which is resistent to bacterial wilt and tomato mosaic viruses. Seed Sci. Technol. 26, 3-7.

Cuartero, J., Romero-Aranda, R., Yeo, A.R., Flowers, T.J. 2002. Variability for some physiological characters affecting salt tolerance in tomato. Acta. Hort. 573, 435-441.

Daei, G., Ardekani, M.R., Rejali, F., Teimuri, S., Miransari, M. 2009. Alleviation of salinity stress on wheat yield, yield components, and nutrient uptake using arbuscular mycorrhizal fungi under field conditions. J. Plant Physiol. $166,617-625$.

Debouba, M., Gouia, H., Suzuki, A., Ghorbel, M.H. 2006. $\mathrm{NaCl}$ stress effects on enzymes involved in nitrogen assimilation pathway in tomato "Lycopersicon esculentum" seedlings. J. Plant Physiol. 163, 1247-1258. 
Estrada, B.E., Aroca, R., Barea, J.M., Ruiz-Lozano, J.M. 2013. Native arbuscular mycorrhizal fungi isolated from a saline habitat improved maize antioxidant systems and plant tolerance to salinity. Plant Sci. 201, 43-51.

Evelin, H., Kapoor, R., Giri, B. 2009. Arbuscular mycorrhizal fungi in alleviation of salt stress: a review. Ann. Bot. 104, 1263-1280.

Feng, G., Zhang, F.S., Li, X.L., Tian, C.Y., Tang, C., Rengel, Z. 2002. Improved tolerance of maize plants to salt stress by arbuscular mycorrhiza is related to higher accumulation of soluble sugars in roots. Mycorrhiza. 12, 185-190.

Ghazi, N., Al-Karaki, R., Rusan, H.M. 2001. Response of two tomato cultivars differing in salt tolerance to inoculation with mycorrhizal fungi under salt stress. Mycorrhiza. 11, 43-47.

Giri, B., Kapoor, R., Mukerji, K.G. 2003. Influence of arbuscular mycorrhizal fungi and salinity on growth, biomass, and mineral nutrition of Acacia auriculiformis. Biol. Fert. Soils. 38, 170-175.

Kjeldahl, J. 1883. A new method for the determination of nitrogen in organic matter. Z. Anal. Chem. 22, 366-382.

Koske, R. E., Gemma, J.W. 1989. A modified procedure for staining roots to detect VA mycorrhizae. Mycol. Res. 92, 486-505.

Lin, T.C., Hung, S.T. 2002. The development of new tomato variety - Taichung Asveg No. 10. Report of Taichung District Agricultural Research and Extension Station, ROC. 75, 41-57.

Linderman, R.G., Davis, E.A. 2004. Vesicular arbuscular mycorrhizal and plant growth response to soil amendment with composed grape promac or its water extract. Phyton. Anals. Botanicase. 11, 446-450.
Mehlich, A. 1984. Mehlich 3 soil test extractant: a modification of Mehlich 2. Comm. Soil Sci. Plant Anal. 15, 1409-1416.

Miller, R.O. 1998. Nitric-perchloric Acid Wet Digestion in an Open Vessel. In: Y. P. Kalra (ed). Handbook of Reference Methods for Plant Analysis. CRC, Boca Raton, pp: 69-73.

Nzanza, B., Marais, D., Soundy, P. 2012. Response of tomato (Solanum lycopersicum L.) to nursery inoculation with Trichoderma harzianum and arbuscular mycorrhizal fungi under field conditions. Acta. Agr. Scand. B-S P. 62, 209-215.

Passam, H.C., Karapanos, I.C., Bebeli, P.J., Savvas, D. 2007. A review of recent research on tomato nutrition, breeding and post-harvest technology with reference to fruit quality. Eur. J. Plant Sci. Biotechnol. 1, 1-21.

Porcel, R., Aroca, R., Ruiz-Lozano, J.M. 2012. Salinity stress alleviation using arbuscular mycorrhizal fungi. A review. Agron. Sustain. Dev. 32, 181-200.

Singh, S., Rekha, P.D., Arun, A.B., Huang, Y.M., Shen, F.T., Young, C.C. 2011. Wastewater from monosodium glutamate industry as a low cost fertilizer source for corn (Zea mays L.) Biomass. Bioenerg. 35, 4001-4007.

Siyal, A. A., Siyal, A.G., Abro, Z.A. 2002. Salt affected soils their identification and reclamation. Pak. J. Appl. Sci. 2, 537-540.

Sonneveld, C., Welles, W.H. 1988. Yield and quality of rockwool-grown tomatoes as affected by variations in EC-value and climatic conditions. Plant Soil. 111, 37-42.

Taiwan Agricultural Research Institute. 1999. Introduction to a novel crop cultivar. (21). Plant Genetic Resources Newsletter of R.O.C. 4 (2) 
Wang, Y.P., Wu, J.T. 1990. The Theory and Practice of Liquid Medium. In: Taiwan Agricultural Research Institute, Department of Agriculture and Forestry, Taiwan Provincial Government (ed). Technical workshop on Issues associated with Hydroponic Culture (the 3rd series). Taiwan Agricultural Research Institute, Taichung, Taiwan, R. O. C., pp: 14-26

Wu, G.G., Lin, S.C. 1998. Taxonomic Studies on Endogonales and Glomales Isolated from Taiwan. In: Taiwan Agricultural Research Institute, Wufeng, Taichung, Taiwan, R. O. C (ed). Technical manual of vesicular-arbuscular mycorrhizal fungi, pp: 54 .
Yuang, B., Li, Z., Liu, H., Gao, M., Zhang, Y. 2007. Microbial biomass and activity in salt affected soils under arid conditions. Appl. Soil Ecol. 35, 319-328.

Zhu, F.C. 1999. Reclamation, utilization and management of salted soils in Taiwan. Soil Environ. 2, 99-116 .

Zwiazek, J.J., Blake, T.J. 1991. Early detection of membrane injury in black spruce (Picea mariana). Can. J. For. Res. 21, 401-404. 